\title{
Improving dyeability and antibacterial activity of Lawsonia inermis $L$ on jute fabrics by chitosan pretreatment
}

\author{
Muhammad Abdur Rahman Bhuiyan ${ }^{1 *}$, Ariful Islam, Shafiqul Islam¹, Anowar Hossain² and Kamrun Nahar ${ }^{3}$
}

\begin{abstract}
This paper investigates the dyeing and antimicrobial properties of jute fiber with natural dye henna after treatment with biopolymer chitosan. The treatment was carried out by applying chitosan solution on the fiber followed by dyeing with henna dye. Then, the performance was assessed in terms of the depth of shade by measuring K/S value and colorfastness properties of chitosan-treated dyed fabric samples. It has been observed that chitosantreated fabrics showed a higher depth of shade compared to untreated dyed samples. As far as colorfastness is concerned, the dyed samples with and without chitosan pretreatment exhibited almost similar dry rubbing fastness. However, chitosan-treated fabrics showed inferior fastness ratings for wet rubbing and washing, particularly for the fabrics with higher chitosan concentrations. Again, the experimental results demonstrated that the combination of chitosan and henna dye can significantly enhance the antibacterial activity of jute fiber against the organism Staphylococcus aureus and Klebsiella pneumoniae. These findings suggest that the application of chitosan and natural dye from henna onto jute fiber is an approach to get the desired dyeing and antibacterial property.
\end{abstract}

Keywords: Jute fiber, Chitosan, Henna dye, Dyeability, Antimicrobial properties

\section{Background}

Jute is a natural lignocellulosic fiber which constitutes $\alpha$ cellulose along with hemicellulose and lignin (Lewin 2006). This fiber is increasingly popular due to its biodegradability, high tensile strength, and better permeability (Bhuiyan et al. 2013; Ghosh et al. 2004). Therefore, the demand of naturally biodegradable and eco-friendly fibers like jute is rising gradually in recent times because of greater global ecological awareness (Wang et al. 2008).

The dyeing of jute fiber can be carried out with a wide range of synthetic dyestuffs, such as direct, vat, basic, and reactive dyes (Bhuiyan et al. 2016a). These dyes are attractive as textile colorants due to their availability, economical, brilliant shades, and excellent color fastness properties, but to some extent these synthetic dyes are allergic, carcinogenic, and detrimental to human health (Siva 2007). For this reason, there has been a revival of the growing interest on the application of non-allergic,

\footnotetext{
* Correspondence: arahman@duet.ac.bd

${ }^{1}$ Department of Textile Engineering, Dhaka University of Engineering and Technology, Gazipur, Bangladesh

Full list of author information is available at the end of the article
}

non-toxic, and eco-friendly natural dyes on natural fibers like jute because of their high compatibility with the environment, as well as the availability of various natural coloring resources (Samanta and Agarwal 2009).

A number of research studies (Pan et al. 2003; Deo and Desai 1999) were performed on the dyeing of jute fiber with several natural dyes such as deodara, jackfruit, eucalyptus leaf, and tea. In addition, jute fiber can also be dyed with the extract of the leaves of henna commonly known as lawsone or hennotannic acid. Chemically, the molecule of lawsone is 2-hydroxy-1,4-naphthoquinone (Scheme 1), a red-orange pigment which is the chief constituent of henna leaves (Rehman et al. 2012). Industrial classifications also depict lawsone as Natural Orange 6 and CI 75480 (Saxena and Raja 2014); it acts as a substantive dye for protein fiber and imparts an orange color on the substrate (Gulrajani et al. 1992). However, some intrinsic limitations such as poor color fastness properties and low substantivity of henna dye towards cellulose hinder its widespread applications on jute and other cellulosic fibers. This may be ascribed to the polar nature of both cellulose and lawsone (hydroxyl groups are usually active sites) and 


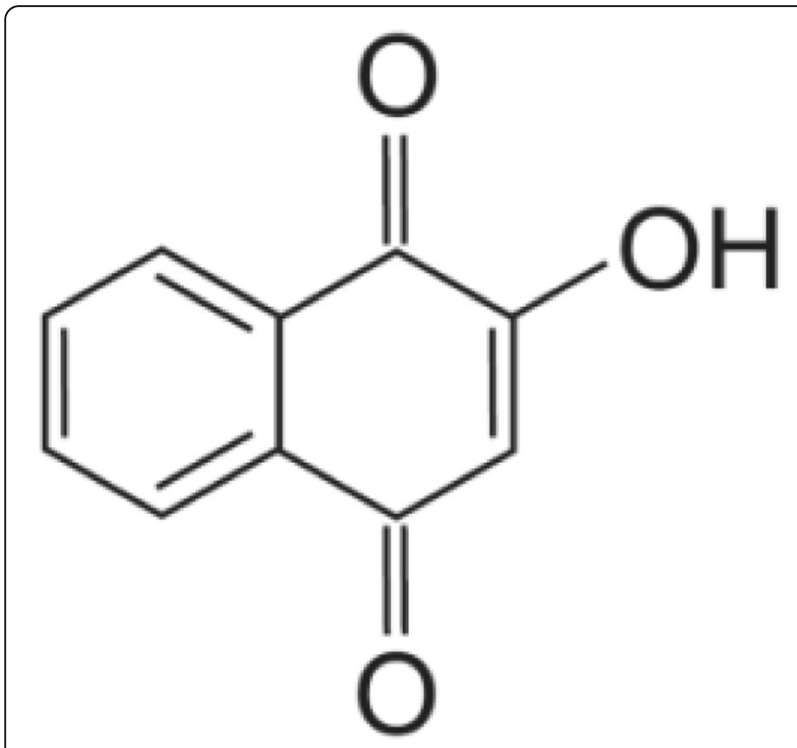

Scheme 1 Chemical structure of lawsone (2-hydroxy-1,4-naphthoquinone)

also complexity of natural aspects (Omer et al. 2015). Therefore, many attempts have been made to elucidate the functional aspects of henna dye in order to enhance its fastness properties.

The introduction of cationic sites within the cellulose is a novel treatment not only to increase the dye adsorption but also to enhance the color strength and fastness properties of dyed fiber (Bashar and Khan 2013). Cationic sites can be introduced to the cellulose polymer through aminization technique by applying chitosan on jute fiber. The chemical structure of chitosan is very similar to that of cellulose which consists of several hundreds to more than a thousand $\beta-(1-4)$ linked D-glucose units (Islam et al. 2016) (Scheme 2). A variety of methods namely pad-dry, pad-dry-steam, pad-batch, and exhaustion (Houshyar and Amirshahi 2002) can be used for the application of chitosan on cellulosic fiber to initiate crosslink (Lee et al. 2010), resulting in the formation of positive dyesites on the fiber surface (Bhuiyan et al. 2014).

The chitosan treatment of textiles is considered as a multi-functional finish as the chemical aspects not only enhance color strength but also contribute to the microbial reduction of textile materials (Tang et al., 2016) and thus have garnered considerable interests of the researchers across the globe. The antimicrobial activity of chitosan is well-documented. It is attributed to the polycationic nature of chitosan which most likely can interact with the predominantly anionic components resulting in changes in permeability that leads to the death of cells by inducing leakage of intracellular components (Klaykruayat et al. 2010). This antibacterial

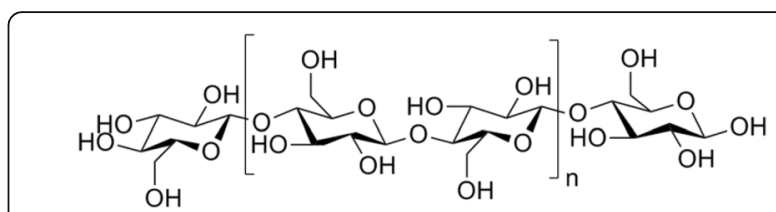

(a)

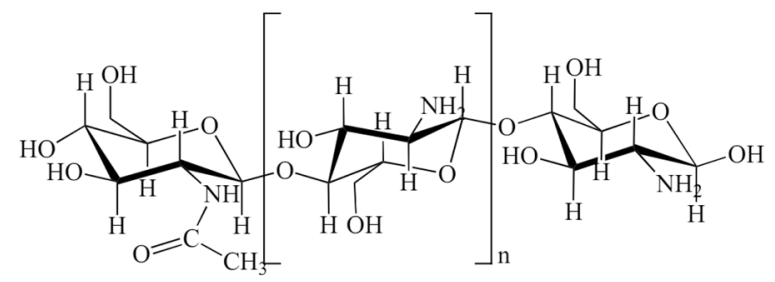

(b)

Scheme 2 Structural relationships between cellulose (a) and chitosan (b)

characteristic leads to a considerable enhancement of microbial resistance of textile materials following treatment with chitosan.

In addition, extracts of henna leaves are capable of inhibiting the growth of both gram-positive and gramnegative bacteria. In the past, several studies (Ali et al. 2001; Bonjar 2004) have explored the antimicrobial properties of henna extracts against the microorganisms Staphylococcus aureus, Escherichia coli, Klebsiella pneumoniae, Pseudomonas aeruginosa, and Proteus mirabilis. The effectiveness of henna was also observed in the management of wound infections and also against the primary invaders of burn wounds (Nayak et al. 2007; Muhammad and Muhammad 2005). However, the combined antimicrobial effect of chitosan and natural dyes on cellulosic fiber like jute has not been yet investigated. Hence, the main objectives of this study were to explore the synergic effect of chitosan and henna on microbial reduction in jute fiber followed by the analysis of dyeability and color strength of henna dye on jute fiber being treated with chitosan.

\section{Experimental \\ Materials}

Scoured, bleached $100 \%$ plain hessian jute fabric (261 GSM) was purchased from the local market of Bangladesh and used in all the experiments. For the dyeing of jute fabric, natural dye henna (Lawsonia inermis) was brought from the local market and used to obtain the dyestuff of lawsone, which is reddish brown in color. A commercial grade water soluble chitosan (straw yellow powder, deacetylation $=95.3 \%$ ) was collected from Zhengzhou Sigma Chemical Company Ltd., China, and used as received in all experiments without any physical or chemical modification. Analytical grade acetic acid $\left(\mathrm{CH}_{3} \mathrm{COOH}\right)$ from Merck, India, was used to dissolve the chitosan in water. 
Ethanol $\left(\mathrm{C}_{2} \mathrm{H}_{5} \mathrm{OH}\right)$ for the extraction of dye from henna leaves was purchased from Merck, India. Antimicrobial activity of the chitosan-treated cotton fabric was examined against the organisms S. aureus (gram-positive) and $K$. pneumoniae (gram-negative) were obtained from the Department of Microbiology, University of Dhaka, Bangladesh.

\section{Methods}

\section{Treatment of jute fiber with chitosan}

For the treatment of jute fiber with chitosan, 0.25, 0.5, 1.0 , and $1.5 \%(w / v)$ concentrations of chitosan solution were prepared at room temperature by dissolving the required amount of chitosan powder in $2 \%(v / v)$ acetic acid solution and stirring the dispersion for $1 \mathrm{~h}$ at $60{ }^{\circ} \mathrm{C}$. The scoured and bleached jute fabrics were then immersed in chitosan solutions of different concentrations for $24 \mathrm{~h}$ at room temperature. The fabrics were then padded by using the Laboratory Padding Mangle from Copower Technology Ltd., Taiwan. The padding of fabric samples was performed at room temperature, $2 \mathrm{~kg} / \mathrm{cm}^{2}$ pressure, squeezed to remove excess solution, and cured in the curing chamber at $120{ }^{\circ} \mathrm{C}$ for $5 \mathrm{~min}$. For the ease of identification, all the test fabric samples were coded as shown in Table 1.

\section{Extraction of natural dye from henna}

Fresh leaves of henna were dried in the sunlight for 1 day and again dried at $80{ }^{\circ} \mathrm{C}$ for $1 \mathrm{~h}$ in a hot air oven following washing and cleaning with distilled water. Dried leaves were grinded to powder form for getting proper extraction result. The extraction of dye was obtained after immersing $20 \mathrm{~g}$ henna powder in $100 \mathrm{~mL}$ water-ethanol mixture $(90: 10 v / v)$ for $24 \mathrm{~h}$. This dye extract solution was used for the dyeing of both chitosan-treated and untreated jute fabric samples.

\section{Dyeing with henna dyes}

The dyeing of treated and untreated jute fiber was carried out using the required amount of extracts in water-ethanol mixture for $45 \mathrm{~min}$ at $75{ }^{\circ} \mathrm{C}$ temperature with material-to-liquor ratio 1:30 for optimum dye exhaustion. The dyeing was performed in Sandolab infrared lab dyeing machine from Copower Technology

Table 1 Test fabric sample coding

\begin{tabular}{ll}
\hline Test fabric type & Code \\
\hline Untreated and undyed fabric sample & U \\
Untreated and dyed fabric sample & A \\
$0.25 \%$ chitosan-treated and dyed fabric sample & B \\
$0.5 \%$ chitosan-treated and dyed fabric sample & $C$ \\
$1.0 \%$ chitosan-treated and dyed fabric sample & D \\
$1.5 \%$ chitosan-treated and dyed fabric sample & E \\
\hline
\end{tabular}

Ltd., Taiwan. After dyeing, the dyed fabric samples were rinsed with cold water and washed in a bath with $1 \mathrm{~g} / \mathrm{L}$ of soaping agent at $60{ }^{\circ} \mathrm{C}$ temperature for $10 \mathrm{~min}$ and then dried in a dryer.

\section{Measurement of color strength and related parameters}

The dyeing performance of treated jute fabric samples with henna dye was analyzed using color measurement spectrophotometer (Datacolor 650 from China) in terms of depth of color and color difference from untreated dyed jute fabric sample. The depth of color of the dyed fabric was determined by analyzing the $\mathrm{K} / \mathrm{S}$ value of a given dyed sample through the Kubelka-Munk equation (Eq. (1)) (Bhuiyan et al. 2016b).

$$
\frac{K}{S}=\frac{(1-R)^{2}}{2 R}
$$

where $R=$ reflectance percentage, $K=$ absorption coefficient, and $S=$ scattering coefficient of dyes. This value was derived from the attenuation ratio of light due to absorption and scattering, which was found based on reflectance. The relative color strength of chitosan-treated dyed fabric samples was obtained using Eq. (2) (Yusuf et al. 2012).

$$
\begin{aligned}
& \text { Relative color strength }(\%) \\
& \qquad=\frac{K / S \text { of treated dyed sample }}{K / S \text { of untreated dyed sample }} \times 100
\end{aligned}
$$

The color differences, i.e., CIELab color deviation $\left(\Delta E^{*}\right)$ value was calculated by using Eq. (3) (Broadbent 2001).

$$
\Delta E^{*}=\sqrt{\Delta L^{* 2}+\Delta a^{* 2}+\Delta b^{* 2}}
$$

The values of $L^{*}, a^{*}$, and $b^{*}$ for a given color locate its position in the three-dimensional CIELab color space, and $\Delta L^{*}=$ deviation of lightness; $\Delta a^{*}=$ deviation of color in green-red axis; and $\Delta b^{*}=$ deviation of color in yellow-blue axis. Both the color deviation and depth of shade of dyed fabric was evaluated according to AATCC test method 173-2006 in illuminant D65, large area view, and CIE $10^{\circ}$ standard observer. Each sample was folded twice to give an opaque view, and color reflectance was measured four times at different parts of the fabric surface

\section{Determination of color fastness properties}

The fastness properties of dyed fabric samples, i.e., color fastness to washing was done according to ISO 105 C03:1989 by wash fastness tester (Gyrowash 415/8 from James H. Heal and Co., UK). The change and staining of color due to washing were assessed by comparing the 
untreated fabric with the treated fabric samples with respect to the ratings of color change and color staining gray scales. The evaluation of color fastness to rubbing was performed according to ISO $105 \mathrm{X}$ 12: 2001 by rubbing fastness tester (Crockmeter 670 from James $\mathrm{H}$. Heal and Co., UK). All the analyses of test fabric samples were conducted after conditioning the dyed fabrics in testing atmosphere (temperature $27 \pm 2{ }^{\circ} \mathrm{C}$ and relative humidity $65 \pm 2 \%$ ) for $24 \mathrm{~h}$.

\section{Characterization}

The determination of specific functional groups or chemical bonds that formed between chitosan and cellulose polymer of jute fiber after dyeing with henna was carried out by Fourier transform infrared (FTIR) spectrophotometer (Cary 630) from Agilent Technologies, USA. FTIR spectra were taken by absorption mode and measured by using potassium bromide $(\mathrm{KBr})$ pellets made of finely cut and ground jute fibers.

\section{Antibacterial property testing}

The antimicrobial properties of the chitosan-treated and untreated dyed fabrics were assessed using ASTM E214901, which is a quantitative antibacterial test method intended to assess the resistance of non-leaching antimicrobial treated specimens to the growth of microbes under dynamic contact conditions (Ferrero and Periolatto 2012). Antimicrobial activity of test specimen was observed against $S$. aureus (gram-positive) and $K$. pneumoniae (gram-negative) bacteria. Each culture was suspended in a small amount of nutrient broth, spread on the nutrient agar plate, and incubated at $37{ }^{\circ} \mathrm{C}$ for $24 \mathrm{~h}$. Two single colonies were picked up with an inoculating loop from the agar plate, suspended in a $5-\mathrm{mL}$ nutrient broth, and incubated for $18 \mathrm{~h}$ at $37^{\circ} \mathrm{C}$. The inoculated plates were incubated in an incubator (Binder from USA) at $37{ }^{\circ} \mathrm{C}$ for $18-24 \mathrm{~h}$ and surviving cells being counted in a safety cabinet (Clernair from Belgium) were used to carry out the preparation of bacteria culture and transferred to an agar plate. The antimicrobial activity was expressed in terms of percentage reduction of the organism after contact with the test specimen compared to the number of bacterial cells surviving after contact with the control using Eq. (4). (Arif et al. 2015)

$$
\% \text { Reduction }=\frac{B-A}{B} \times 100
$$

where $A$ and $B$ are the surviving cells (colony forming units per milliliter $(\mathrm{CFU} / \mathrm{mL})$ ) for the flasks containing test samples (chitosan-treated and dyed jute) and the control (untreated and undyed jute), respectively, after $1 \mathrm{~h}$ contact time.

\section{Results and discussion}

\section{Measurement of color strength}

The depth of color or color strength of dyed fabric samples was analyzed by $\mathrm{K} / \mathrm{S}$ value through the Kubelka-Munk equation, the most useful and applicable theoretical approach or model for colorants when colorants exhibit properties of light absorbing and scattering. This value numerically represents the nature of the coloring material layer and an easy way to determine a color as a concentration (Nobbs 1985). The function $\mathrm{K} / \mathrm{S}$ is directly proportional to the concentration of colorant in the substrate, and the values found for all the experimental fabric samples are shown in Fig. 1.

Figure 1 shows the K/S values of dyed fabric samples for different percentages of chitosan treatment. The greater the amount of dyestuff in the fabric, the deeper is the shade, resulting in higher $\mathrm{K} / \mathrm{S}$ values. The longer bar diagram showed by the fabric samples treated with $1.5 \%$ chitosan indicates the greater absorption of dye, whereas fabric without chitosan treatment forms shortest bar due to lower $\mathrm{K} / \mathrm{S}$ value consequently lower absorption of dye (Fig. 2).

The better absorption of henna dye by jute fiber due to chitosan treatment has not been investigated extensively so far. However, chitosan has been proved to increase the rate of dye uptake and dye exhaustion of cellulosic fibers in case of reactive dyes (Kitkulnumchai et al. 2008; Bhuiyan et al. 2013). It may be suggested that the introduction of amino groups in the fiber structure due to chitosan treatment offers an additional affinity (Dev et al. 2009). The cationization of cellulose for the formation of ammonium ion $\left(\mathrm{NH}_{4}^{+}\right)$of chitosan (Bashar and Khan 2013) caused by treatment with jute fiber in acid medium may attract the acidic hydroxylated structure of the coloring component lawsone (2-hydroxy-1,4naphthoquinone) of henna dye (Ali et al. 2009) resulting in higher absorption of dye by the fiber.

\section{Color difference and relative color strength}

The evaluation of the color parameter and the color difference of dyed fabric samples was performed by using CIELab system. The lightness value of color (from 100 to 0 ) is represented by $L^{*}$; a higher lightness value indicates a lower color yield by the dyed fabric. Again, $a^{*}$ and $b^{*}$ values characterize the tone of the color; positive values of $a^{*}$ and $b^{*}$ stand for redder and yellower tones, while negative values show greener and bluer tones (Kuehni 2003).

It can be observed from Table 2 that the $L^{*}$ values decrease with the increase in chitosan concentration indicating that the sample becomes darker compared to the untreated dyed sample. The reduced lightness value of dyed fabric samples signifies greater absorption of dye 


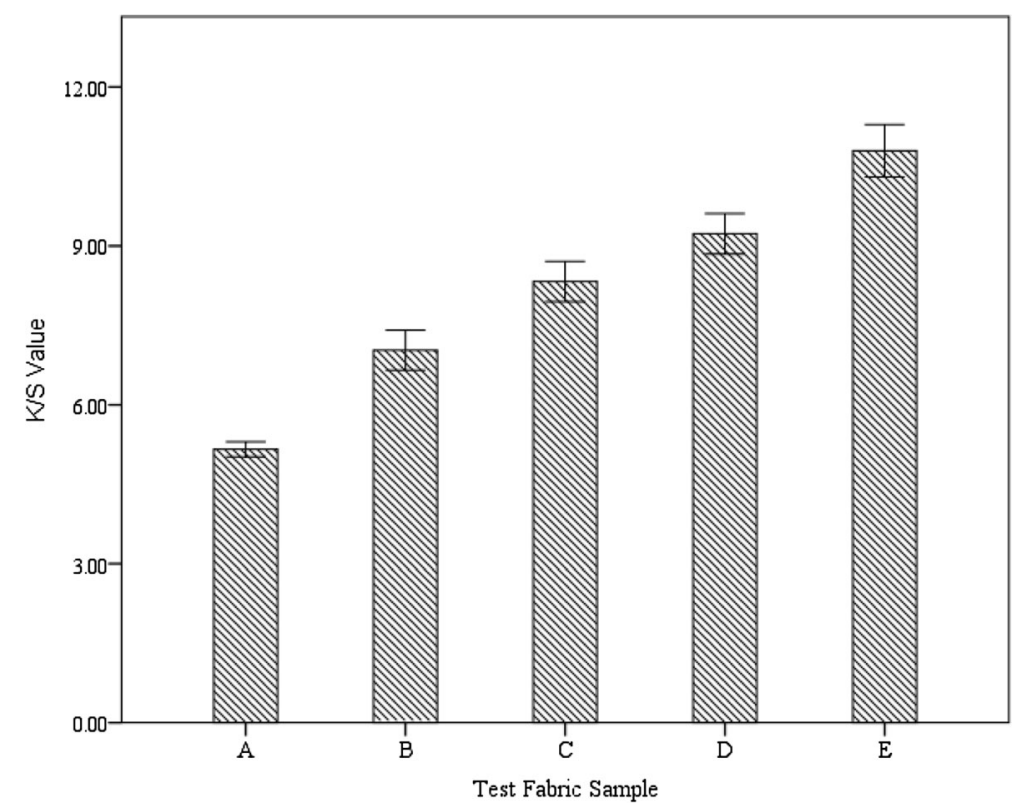

Fig. 1 The gradual improvement of dye absorption (K/S value) of jute fiber with the increment of chitosan concentration

and consequently higher relative strength of color. Moreover, the positive $a^{*}$ and $b^{*}$ values suggest the combination of red and yellow tones resulting in the orange color of the dyed fabric sample which is the characteristic natural color of the lawsone pigment of henna dye.

The color difference $(\Delta E)$ values are also given in Table 2 and it is clearly demonstrated that there is a significant color difference between the untreated and chitosan-treated dyed samples. The color difference is more prominent in the case of fabric samples treated with $1.5 \%$ chitosan solution, and it decreases steadily with the reduction in chitosan concentration. The larger color difference with the increment of chitosan concentration is due to the greater absorption of dye by the fiber and accordingly leads to a higher $K / S$ value with chitosan concentration.

\section{Color fastness properties of dyed fabric}

Color fastness is the property of a dye to retain its color when the dyed or printed textile material is exposed to washing or other conditions. The assessment of color fastness properties (rubbing and washing) of dyed textile material is carried out using the gray scale. Gray scales are used to measure the color fastness against washing by color change and color staining (with multifiber fabric) options (Saville, 1999). However, rubbing fastness of dyed fabric samples was evaluated only by color staining option in both dry and wet conditions. The color fastness ratings of all experimental dyed fabric samples are tabulated in Tables 3 and 4.

The wash fastness ratings in Table 3 show that chitosantreated and untreated jute fabrics dyed with henna dye have almost identical fastness ratings of "good" to "excellent" (within numerical grades 4-5) with very little variation. Again, the staining of color to adjacent multifiber fabric has been found higher for chitosan-treated dyed samples (D, E) particularly in cotton and wool fiber (3-4 and 3). Moreover, in case of dry rubbing (Table 4), all types of dyed samples have shown almost similar ratings; however, chitosan-treated samples with higher concentrations represent a lower rating (3-4) compared to untreated samples (4-5) for wet rubbing. In general, deeper shade shows inferior fastness to washing and rubbing than a lighter one on a similar type of fabric for the same dyestuff (Bhuiyan et al. 2013), because in case of deep shade, dye molecules are more saturated and tend to move out from the interior of the fiber due to washing. As discussed earlier, the chitosan present in the fabric enhances the



Sample A

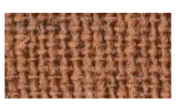

Sample B

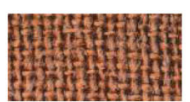

Sample C

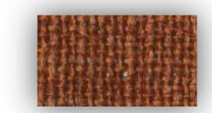

Sample D

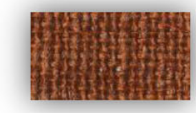

Sample E

Fig. 2 Shade card of treated and untreated jute fabric samples dyed with henna dye 
Table 2 Spectrophotometer characterization of chitosan-treated and untreated henna dyed jute fabric samples

\begin{tabular}{llllll}
\hline $\begin{array}{l}\text { Test fabric } \\
\text { samples }\end{array}$ & $\begin{array}{l}\text { Relative color } \\
\text { strength (\%) }\end{array}$ & $L^{*}$ & $a^{*}$ & $b^{*}$ & $\Delta E$ value \\
\hline A & 100 & 55.85 & 9.14 & 17.07 & - \\
B & 135 & 54.45 & 9.27 & 17.14 & 1.74 \\
C & 160 & 53.71 & 9.67 & 17.76 & 2.66 \\
D & 180 & 52.08 & 10.34 & 17.81 & 3.51 \\
E & 210 & 51.24 & 10.51 & 18.33 & 4.12 \\
\hline
\end{tabular}

dyesite causing higher absorption of dye resulting in a higher depth of shade. Hence, as a general consequence of achieving deeper shade, the chitosan-treated fabric samples have shown a slightly lower fastness rating in comparison to lighter, untreated fabric.

\section{Characterization of dyed fabric samples FTIR spectroscopic analysis}

The structural properties of chitosan-treated and untreated jute fiber after dyeing with henna dyes were investigated by FTIR spectroscopy. This analytical technique provides information about the chemical bonds and molecular structure of a material. The existence of a specific chemical bond in any material is indicative of the presence of a peak at a specific wavenumber being revealed through scanning the test samples in the infrared light source.

The chemical interaction between chitosan and jute fiber polymer is investigated by the change of the peaks from the characteristic spectra as shown in Fig. 3. In general, no significant changes were observed in bands or their intensities in case of all test fabrics. The broad absorption band which appears in the range of 3500$3100 \mathrm{~cm}^{-1}$ indicates the presence of $-\mathrm{OH}$ groups in the cellulose polymer (Agarwal and Bhattacharya 2010). However, the strong absorption in the region 3500$3100 \mathrm{~cm}^{-1}$ in case of chitosan-treated fiber signifies the strong hydrogen bonded chitosan and jute fiber and also the existence of primary $-\mathrm{NH}_{2}$ and secondary $-\mathrm{NH}$ groups (Bhuiyan et al. 2016c). The presence of $-\mathrm{NH}_{2}$ group in the treated fabric is responsible for introducing

Table 3 Color fastness to washing (color change and color staining) of untreated and chitosan-treated dyed jute fabric samples

\begin{tabular}{|c|c|c|c|c|c|c|c|}
\hline \multirow{3}{*}{$\begin{array}{l}\text { Test fabric } \\
\text { samples }\end{array}$} & \multicolumn{7}{|c|}{ Washing fastness ratings } \\
\hline & \multirow{2}{*}{$\begin{array}{l}\text { Color } \\
\text { change }\end{array}$} & \multicolumn{6}{|c|}{ Color staining } \\
\hline & & Acetate & Cotton & Nylon & Polyester & Acrylic & Wool \\
\hline A & $4-5$ & $4-5$ & 4 & $4-5$ & $4-5$ & $4-5$ & $4-5$ \\
\hline B & $4-5$ & $4-5$ & 4 & $4-5$ & $4-5$ & $4-5$ & $4-5$ \\
\hline C & $4-5$ & $4-5$ & $3-4$ & $4-5$ & $4-5$ & $4-5$ & 4 \\
\hline D & 4 & $4-5$ & $3-4$ & $4-5$ & $4-5$ & $4-5$ & 4 \\
\hline E & 4 & $4-5$ & 3 & $4-5$ & $4-5$ & $4-5$ & 4 \\
\hline
\end{tabular}

Table 4 Color fastness to rubbing (dry and wet) of untreated and chitosan-treated dyed jute fabric samples

\begin{tabular}{|c|c|c|c|c|}
\hline \multirow[t]{2}{*}{$\begin{array}{l}\text { Test fabric } \\
\text { samples }\end{array}$} & \multicolumn{2}{|c|}{$\begin{array}{l}\text { Rubbing fastness } \\
\text { (warp direction) }\end{array}$} & \multicolumn{2}{|c|}{$\begin{array}{l}\text { Rubbing fastness } \\
\text { (weft direction) }\end{array}$} \\
\hline & Dry & Wet & Dry & Wet \\
\hline A & $4-5$ & $4-5$ & $4-5$ & $4-5$ \\
\hline B & $4-5$ & $4-5$ & $4-5$ & 4 \\
\hline$C$ & $4-5$ & 4 & $4-5$ & 4 \\
\hline $\mathrm{D}$ & $4-5$ & $3-4$ & $4-5$ & $3-4$ \\
\hline $\mathrm{E}$ & 4 & $3-4$ & 4 & $3-4$ \\
\hline
\end{tabular}

a cationic site in jute polymer resulting in improved dye exhaustion and also interaction with microorganisms for antibacterial properties. Again, the spectrum near $2900 \mathrm{~cm}^{-1}$ corresponding to the symmetric stretching of methylene $\left(-\mathrm{CH}_{2}-\right)$ groups (Davulcu et al. 2014) and $1735 \mathrm{~cm}^{-1}$ related to the $\mathrm{C}=\mathrm{O}$ stretch of esters were found to be similar in all the tested samples. The absorption peak that appeared at $1640 \mathrm{~cm}^{-1}$ for chitosan-treated jute suggested the formation of Schiff base $(\mathrm{C}=\mathrm{N}$ double bond) between aldehydic carbonyl group of cellulose and amino group of chitosan. All three samples showed peaks near 1430 and $1325 \mathrm{~cm}^{-1}$, being related to $-\mathrm{OH}$ bending of $\mathrm{C}-\mathrm{O}-\mathrm{H}$ alcohol groups and $1060 \mathrm{~cm}^{-1}$ corresponding to $\mathrm{C}-\mathrm{O}$ mainly of $\mathrm{C}_{3}-\mathrm{O}_{3} \mathrm{H}$ secondary alcohol. Moreover, the peak at $898 \mathrm{~cm}^{-1}$ corresponding to asymmetric out-of-phase ring stretching of C1-O-C4 $\beta$-glucosidic bonds (Chung et al. 2004) was increased after the dyeing process.

\section{Improvement of antimicrobial properties}

The antibacterial activity of chitosan-treated and untreated dyed jute fabric samples were carried out against S. aureus (gram-positive) and K. pneumoniae (gram-negative) bacteria. The pathogenic gram-positive bacterium $S$. aureus is the most frequently evaluated species, commonly found in the nose, respiratory tract, and on the skin, the major cause of cross-infection in hospitals as well as in commercial and home laundry practices (Kluytmans et al. 1997). It causes skin and tissue infections, respiratory infections, and food poisoning (Weese and van Duijkeren 2010). Again, the gramnegative bacterium $K$. pneumonia, which is a popular test organism, is found in the normal flora of the mouth, skin, and intestines and can cause severe bacterial infections leading to pneumonia, bloodstream infections, wound infections, urinary tract infections, and meningitis (Eliopoulos et al. 2008).

The reduction of microorganisms ( $S$. aureus and $K$. pneumoniae) on chitosan-treated dyed jute fabrics are shown in Table 5 respectively. In case of untreated and undyed fabric samples, no antibacterial activity was observed against S. aureus and K. pneumoniae. However, 

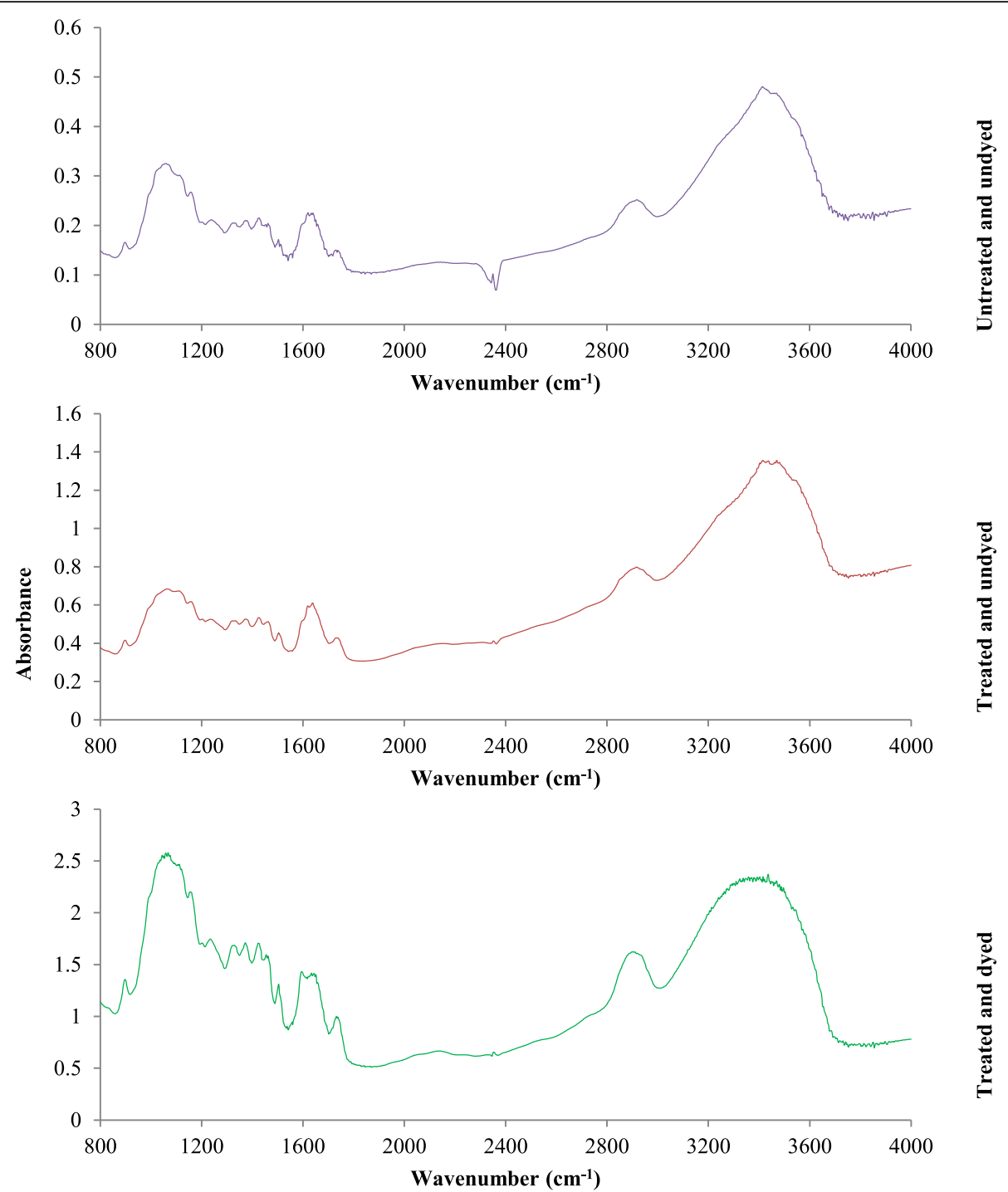

Fig. 3 FTIR absorption spectra of selected jute fabric samples

Table 5 Microbial reduction percentages of henna dyed jute fabrics with the increment of chitosan concentration against S. aureus (gram-positive) and K. pneumoniae (gram-negative) bacteria

\begin{tabular}{|c|c|c|c|c|}
\hline \multirow{2}{*}{$\begin{array}{l}\text { Organism } \rightarrow \\
\text { Fabric samples } \downarrow\end{array}$} & \multicolumn{2}{|l|}{ S. aureus } & \multicolumn{2}{|l|}{ K. pneumoniae } \\
\hline & Surviving cells (CFU/mL) & Reduction (\%) & Surviving cells (CFU/mL) & Reduction (\%) \\
\hline $\bar{U}$ & $2.55 \times 10^{5}[\mathrm{~B}]$ & & $2.80 \times 10^{5}[\mathrm{~B}]$ & \\
\hline A & $1.32 \times 10^{5}[\mathrm{~A}]$ & 48.2 & $1.94 \times 10^{5}[\mathrm{~A}]$ & 30.7 \\
\hline B & $28.0 \times 10^{3}[\mathrm{~A}]$ & 89.0 & $50.0 \times 10^{3}[\mathrm{~A}]$ & 82.1 \\
\hline C & $22.0 \times 10^{3}[\mathrm{~A}]$ & 91.4 & $21.0 \times 10^{3}[\mathrm{~A}]$ & 92.5 \\
\hline D & $15.0 \times 10^{3}[\mathrm{~A}]$ & 94.1 & $17.0 \times 10^{3}[\mathrm{~A}]$ & 93.9 \\
\hline$E$ & $11.0 \times 10^{3}[\mathrm{~A}]$ & 95.8 & $15.0 \times 10^{3}[\mathrm{~A}]$ & 94.6 \\
\hline
\end{tabular}

CFU/ml: Colony Forming Units per milliliter which is mentioned in the experimental section 

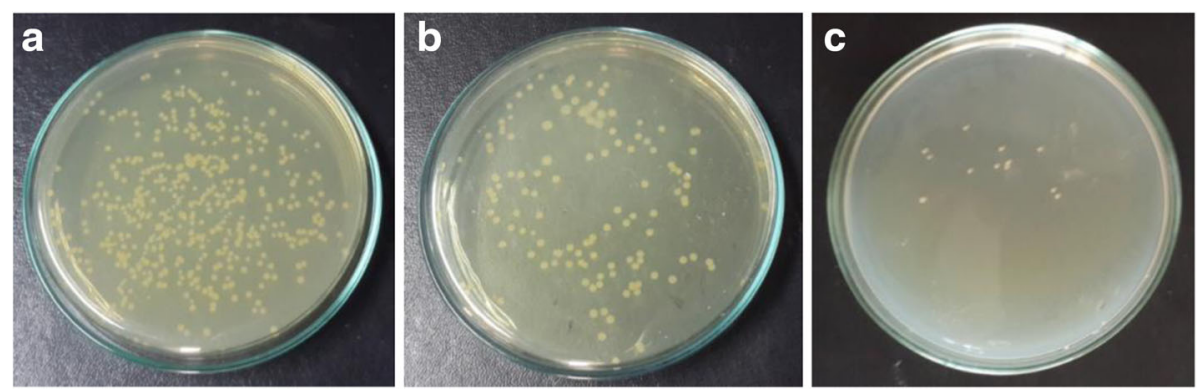

Fig. 4 Number of surviving cells (S. aureus) after contact with untreated and undyed (a), untreated and dyed (b), and chitosan-treated (1.5\%) dyed fabric sample (c)

jute fabrics dyed with henna dye following the treatment with chitosan demonstrated a significant improvement of antibacterial property against both organisms (Figs. 4 and 5) which revealed a wide spectrum activity and a high killing rate of chitosan against gram-positive and gram-negative bacteria. Furthermore, the microbial inhibition was found to be increased with the increase in chitosan concentration. The most accepted mechanism for the microbial reduction by chitosan is its polycationic structure which causes death of the cell by interacting with anionic proteins of microorganisms (Lim and Hudson, 2004). Moreover, the strong electrostatic interaction which is caused by higher positive charge density adsorbs the electronegative substance in the cell and disturbs the physiological activities of the microorganism (Bhuiyan et al. 2016c; Zheng and Zhu 2003). There are several intrinsic and extrinsic factors, such as $\mathrm{pH}$, microorganism species, positive charge density, molecular weight (MW), and the degree of deacetylation (DD) of chitosan can influence the antimicrobial activity (Zivanovic et al. 2004), while the density of cations depends on the concentration of chitosan and its degree of substitution resulting in a greater reduction of microorganism with the increment of chitosan concentration.

On the other hand, fabrics dyed with henna alone without chitosan application also exhibit antimicrobial activity especially in case of $S$. aureus bacteria in Table 5 .
Moreover, the presence of residual ethanol influences the antibacterial property of henna dye due to ethanolic extraction. Several studies showed that the ethanolic extraction of $L$. inermis is the most active against all the bacteria in the test system compared to aqueous extraction of henna dye (Sukanya et al. 2009; Ali et al. 2001). In addition, the presence of colored pigment lawsone (2-hydroxy-1,4-naphthoquinone) is also responsible for the inherent antimicrobial activity of henna dye. The highly reactive nature of ketone groups $(>\mathrm{C}=\mathrm{O})$ in the aromatic ring of quinones of lawsone exhibits the antimicrobial property by forming a complex irreversibly with nucleophilic amino acids in proteins and leading to inactivation of the protein and loss of function (Dev et al. 2009). Hence, the natural antimicrobial efficacy of henna dye can be enhanced considerably by coupling with chitosan for the application on textile materials to protect the clothes against common infections.

\section{Conclusions}

The treatment of jute fiber with the biopolymer chitosan and its effect on dyeing with natural colorants and antibacterial characteristics of fiber has been investigated. The detailed study has demonstrated the twofold effect of chitosan on jute fiber. The treatment of jute with chitosan can appreciably enhance the uptake of dye by the
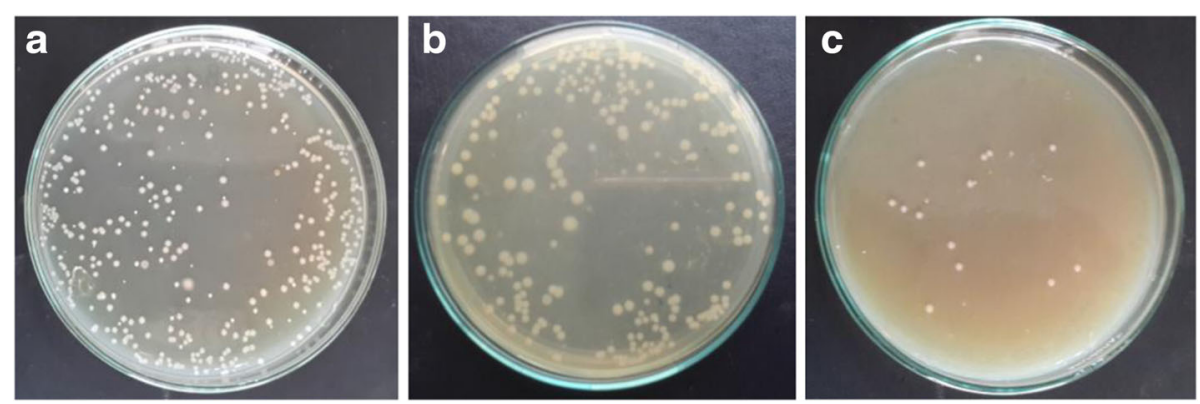

Fig. 5 Number of surviving cells (K. pneumoniae) after contact with untreated and undyed (a), untreated and dyed (b), and chitosan-treated (1.5\%) dyed fabric sample (c) 
fiber. Moreover, the color fastness property of dyed fabrics against washing and rubbing also exhibits within the acceptable range of good to excellent. On the other hand, the antimicrobial activities of jute fabric increase significantly due to the combined effect of natural dye henna and biopolymer chitosan. Thus, the findings of the study suggest a potential application of chitosan as a non-toxic, eco-friendly, and multi-functional finish providing the desired dyeing and antimicrobial properties of jute fiber after treatment with chitosan.

\section{Authors' contributions}

MAR conceived of the study, designed the experiment and drafted the manuscript. Al and KN coordinated experimental analysis and manuscript submission. SI and AH interpreted data and drafting the manuscript. All authors read and approved the final manuscript submission.

\section{Competing interests}

The authors declare that they have no competing interests.

\section{Author details}

'Department of Textile Engineering, Dhaka University of Engineering and Technology, Gazipur, Bangladesh. Department of Textile Engineering, Primeasia University, Dhaka, Bangladesh. ${ }^{3}$ Department of Microbiology, Primeasia University, Dhaka, Bangladesh.

Received: 8 November 2016 Accepted: 11 December 2016

Published online: 05 January 2017

\section{References}

Agarwal, B. J., \& Bhattacharya, S. D. (2010). Possibilities of polymer aided dyeing of cotton fabric with reactive dyes at neutral pH. Journal of Applied Polymer Science, 118, 1257-1269.

Ali, S., Hussain, T., \& Nawaz, R. (2009). Optimization of alkaline extraction of natural dye from henna leaves and its dyeing on cotton by exhaust method. Journal of Cleaner Production, 17(1), 61-66.

Ali, N. A., Jülich, W. D., Kusnick, C., \& Lindequist, U. (2001). Screening of Yemeni medicinal plants for antibacterial and cytotoxic activities. Journal of Ethnopharmacology, 74(2), 173-179.

Arif, D., Niazi, M. B. K., UI-Haq, N., Anwar, M. N., \& Hashmi, E. (2015). Preparation of antibacterial cotton fabric using chitosan-silver nanoparticles. Fibers and Polymers, 16(7), 1519-1526.

Bashar, M. M., \& Khan, M. A. (2013). An overview on surface modification of cotton fiber for apparel use. Journal of Polymers and the Environment, 21(1), $181-190$

Bhuiyan, M.R., Shaid, A., Bashar, M.M., Sarkar, P (2016a) Investigation on dyeing performance of basic and reactive dyes concerning jute fiber dyeing. Journal of Natural Fibers, 13(4): 492-501.

Bhuiyan, M.R., Rahman, M.M., Shaid, A., Bashar, M.M., Khan, M.A. (2016b) Scope of reusing and recycling the textile wastewater after treatment with gamma radiation. Journal of Cleaner Producton, 112(4): 3063-3071.

Bhuiyan, M. R., Hossain, M. A., Zakaria, M., Islam, M. N., Uddin, M. Z. (2016c) Chitosan coated cotton fiber: physical and antimicrobial properties for apparel use. Journal of Polymers and the Environment, 1-9 DOl: 10.1007/ s10924-016-0815-2.

Bhuiyan, M. R., Shaid, A., \& Khan, M. A. (2014). Cationization of cotton fiber by chitosan and its dyeing with reactive dye without salt. Chemistry and Materials Engineering, 2(4), 96-100.

Bhuiyan, M. R., Shaid, A., Bashar, M. M., Haque, P., \& Hannan, M. A. (2013). A novel approach of dyeing jute fiber with reactive dye after treating with chitosan Open Journal of Organic Polymer Materials, 3(4), 87-91.

Bonjar, S. (2004). Evaluation of antibacterial properties of some medicinal plants used in Iran. Journal of Ethnopharmacology, 94(2), 301-305.

Broadbent, A. D. (2001). Basic principles of textile coloration society of dyers and colorists, West Yorkshire.

Chung, C., Lee, M., \& Choe, E. K. (2004). Characterization of cotton fabric scouring by FT-IR ATR spectroscopy. Carbohydrate Polymers, 58, 417-420.
Davulcu, A., Benli, H., Şen, Y., \& Bahtiyari, M. I. (2014). Dyeing of cotton with thyme and pomegranate peel. Cellulose, 21(6), 4671-4680.

Deo, H. T., \& Desai, B. K. (1999). Dyeing of cotton and jute with tea as a natural dye. Coloration Technology, 115(7-8), 224-227.

Dev, V. G., Venugopal, J., Sudha, S., Deepika, G., \& Ramakrishna, S. (2009). Dyeing and antimicrobial characteristics of chitosan treated wool fabrics with henna dye. Carbohydrate Polymers, 75(4), 646-650.

Eliopoulos, G. M., Maragakis, L. L., \& Perl, T. M. (2008). Acinetobacter baumannii: epidemiology, antimicrobial resistance, and treatment options. Clinical Infectious Diseases, 46(8), 1254-1263.

Ferrero, F., \& Periolatto, M. (2012). Antimicrobial finish of textiles by chitosan UVcuring. Journal of Nanoscience and Nanotechnology, 12(6), 4803-4810.

Ghosh, P., Samanta, A. K., \& Basu, G. (2004). Effect of selective chemical treatments of jute fibre on textile-related properties and processibility. Indian Journal of Fibre \& Textile Research, 29, 85-99.

Gulrajani, M. L., Gupta, D. B., Aggarwal, V., \& Jain, M. (1992). Some studies on natural yellow dyes, Part III: Quinones: Henna, Dolu. The Indian Textile Journal, 102(3), 76-83.

Houshyar, S., \& Amirshahi, S. H. (2002). Treatment of cotton with chitosan and its effect on dyeability with reactive dyes. Iranian Polymer Journal, 11(5), 295-302.

Islam S, Bhuiyan MR, Islam MN (2016) Chitin and chitosan: structure, properties and application in biomedical engineering. Journal of Polymers and the Environment, 1-13. doi:10.1007/s10924-016-0865-5.

Kitkulnumchai, Y., Ajavakom, A., \& Sukwattanasinitt, M. (2008). Treatment of oxidized cellulose fabric with chitosan and its surface activity towards anionic reactive dyes. Cellulose, 15(4), 599-608.

Klaykruayat, B., Siralertmukul, K., \& Srikulkit, K. (2010). Chemical modification of chitosan with cationic hyperbranched dendritic polyamidoamine and its antimicrobial activity on cotton fabric. Carbohydrate Polymers, 80(1), 197-207.

Kluytmans, J., Van Belkum, A., \& Verbrugh, H. (1997). Nasal carriage of Staphylococcus aureus: epidemiology, underlying mechanisms, and associated risks. Clinical Microbiology Reviews, 10(3), 505-520.

Kuehni, R.G. (2003). Color space and its divisions: color order from antiquity to the present. New Jersey: John Wiley \& Sons.

Lee, S. H., Kim, M. J., \& Park, H. (2010). Characteristics of cotton fabrics treated with epichlorohydrin and chitosan. Journal of Applied Polymer Science, $117(2), 623-628$.

Lim, S. H., \& Hudson, S. M. (2004). Synthesis and antimicrobial activity of a watersoluble chitosan derivative with a fiber-reactive group. Carbohydrate Research, 339(2), 313-319.

Lewin M (Ed.) (2006) Handbook of fiber chemistry. New York: Crc Press.

Muhammad, H. S., \& Muhammad, S. (2005). The use of Lawsonia inermis Linn. (henna) in the management of burn wound infections. African Journal of Biotechnology, 4(9), 934-937.

Nayak, B. S., Isitor, G., Davis, E. M., \& Pillai, G. K. (2007). The evidence based wound healing activity of Lawsonia inermis Linn. Phytotherapy Research 21(9), 827-831.

Nobbs, J. H. (1985). Kubelka—Munk theory and the prediction of reflectance. Review of Progress in Coloration and Related Topics, 15(1), 66-75.

Omer, K. A., Tao, Z., \& Seedahmed, A. I. (2015). New approach for dyeing and UV protection properties of cotton fabric using natural dye extracted from henna leaves. Fibres \& Textiles in Eastern Europe, 5(113), 60-65.

Pan, N. C., Chattopadhyay, S. N., \& Day, A. (2003). Dyeing of jute with natural dyes. Indian Journal of Fibre \& Textile Research, 28(3), 339-342.

Rehman, F. U., Adeel, S., Qaiser, S., Bhatti, I. A., Shahid, M., \& Zuber, M. (2012). Dyeing behaviour of gamma irradiated cotton fabric using Lawson dye extracted from henna leaves (Lawsonia inermis). Radiation Physics and Chemistry, 81(11), 1752-1756.

Samanta, A. K. \& Agarwal, P. (2009). Application of natural dyes on textiles. Indian Journal of Fibre \& Textile Research, 34(4), 384-399.

Saville, B. P. (1999). Physical testing of textiles. Cambridge: Woodhead Publishing Limited.

Saxena, S., \& Raja, A. S. M. (2014). Natural dyes: sources, chemistry, application and sustainability issues. In Roadmap to Sustainable Textiles and Clothing (pp. 37-80). Singapore: Springer

Siva, R. (2007). Status of natural dyes and dye-yielding plants in India. Current Science Bangalore, 92(7), 916-925.

Sukanya, S. L., Sudisha, J., Hariprasad, P., Niranjana, S. R., Prakash, H. S., \& Fathima, S. K. (2009). Antimicrobial activity of leaf extracts of Indian medicinal plants against clinical and phytopathogenic bacteria. African Journal of Biotechnology, 8(23), 6677-6682 
Tang, R., Yu, Z., Zhang, Y., \& Qi, C. (2016). Synthesis, characterization, and properties of antibacterial dye based on chitosan. Cellulose, 23(3), 1741-1749.

Wang, W. M., Cai, Z. S., \& Yu, J. Y. (2008). Study on the chemical modification process of jute fiber. Journal of Engineered Fibers and Fabrics, 3(2), 1-11.

Weese, J. S., \& van Duijkeren, E. (2010). Methicillin-resistant Staphylococcus aureus and Staphylococcus pseudintermedius in veterinary medicine. Veterinary Microbiology, 140(3), 418-429.

Yusuf, M., Ahmad, A., Shahid, M., Khan, M. I., Khan, S. A., Manzoor, N., \& Mohammad, F. (2012). Assessment of colorimetric, antibacterial and antifungal properties of woollen yarn dyed with the extract of the leaves of henna (Lawsonia inermis). Journal of Cleaner Production, 27, 42-50.

Zivanovic, S., Basurto, C. C., Chi, S., Davidson, P. M., \& Weiss, J. (2004). Molecular weight of chitosan influences antimicrobial activity in oil-in-water emulsions. Journal of Food Protection, 67(5), 952-959.

Zheng, L. Y., \& Zhu, J. F. (2003). Study on antimicrobial activity of chitosan with different molecular weights. Carbohydrate Polymers, 54(4), 527-530.

\section{Submit your manuscript to a SpringerOpen ${ }^{\circ}$ journal and benefit from:}

- Convenient online submission

- Rigorous peer review

- Immediate publication on acceptance

- Open access: articles freely available online

- High visibility within the field

- Retaining the copyright to your article

Submit your next manuscript at $\gg$ springeropen.com 